\author{
Abstracta Iranica \\ Abstracta Iranica Revue bibliographique pour le domaine irano-aryen \\ Volume 42-43 | 2021 \\ Comptes rendus des publications de 2019-2020
}

\title{
Christine Chaillot. L'Église assyrienne de l'Orient : histoire bimillénaire et géographie mondiale
}

\section{Christelle Jullien}

\section{(2) OpenEdition}

1 Journals

\section{Édition électronique}

URL : https://journals.openedition.org/abstractairanica/54102

DOI : 10.4000/abstractairanica.54102

ISSN : 1961-960X

Éditeur :

CNRS (UMR 7528 Mondes iraniens et indiens), Éditions de l'IFRI

\section{Référence électronique}

Christelle Jullien, «Christine Chaillot. L'Église assyrienne de l'Orient : histoire bimillénaire et géographie mondiale », Abstracta Iranica [En ligne], Volume 42-43 | 2021, document 19, mis en ligne le 30 décembre 2021, consulté le 01 janvier 2023. URL : http://journals.openedition.org/abstractairanica/54102 ; DOI : https://doi.org/10.4000/abstractairanica.54102

Ce document a été généré automatiquement le 1 janvier 2023.

Tous droits réservés 


\title{
Christine Chaillot. L'Église assyrienne de l'Orient : histoire bimillénaire et géographie mondiale
}

\author{
Christelle Jullien
}

\section{RÉFÉRENCE}

Christine Chaillot. L'Église assyrienne de l'Orient : histoire bimillénaire et géographie mondiale. Paris : L'Harmattan, 2020, 221 p., (Religions et Spiritualité. Série Études), ISBN : 978-2-343-19268-0.

1 L'ouvrage offre une vaste fresque de l'histoire de l'Église d'Orient, au cœur de l'empire perse, avec un regard sur ses différentes traditions apostoliques et sur son expansion missionnaire vers l'Est, l'Inde, la Chine, via le golfe Persique et la route terrestre dite de la soie, depuis ses origines jusqu'au XV $\mathrm{XV}^{\mathrm{e}}$ siècle, date du déclin de ces communautés avec les invasions timourides. L'A. s'intéresse par ailleurs aux Syro-orientaux de la diaspora. Une bonne synthèse pour qui voudrait connaître un peu mieux l'histoire mouvementée de ces chrétiens orientaux qui marquèrent durablement la culture moyen-orientale.

\section{AUTEURS}

CHRISTELLE JULLIEN

CNRS, CeRMI, Paris 